\title{
Bariatric Surgery Survey 2018: Similarities and Disparities Among the 5 IFSO Chapters
}

\author{
Luigi Angrisani ${ }^{1}$ (D) Antonella Santonicola ${ }^{2} \cdot$ Paola lovino $^{2} \cdot$ Almino Ramos $^{3} \cdot$ Scott Shikora $^{4} \cdot$ Lilian Kow $^{5}$
}

Received: 25 September 2020 / Revised: 23 December 2020 / Accepted: 29 December 2020 / Published online: 12 January 2021

(C) The Author(s), under exclusive licence to Springer Science+Business Media, LLC part of Springer Nature 2021

\begin{abstract}
Background The 2018 IFSO Survey focused on similarities and disparities in the number and types of surgical and endoluminal interventions among the IFSO chapters occurred in the last decade.

Methods All IFSO Societies were asked to fill in the IFSO survey form on how many and which surgical and endoluminal interventions have been performed in the 2018. A special section was added, asking about the existence of national guidelines for bariatric and metabolic surgery, national recommendations for preoperative gastroscopy, type of reimbursement for bariatric/ metabolic surgery, including for patients with BMI $<35 \mathrm{~kg} / \mathrm{m}^{2}$. The trend analyses from 2008 to 2018 were also performed.

Results Fifty-seven/65 (87.7\%) IFSO Societies submitted completed forms. The American Society for Metabolic and Bariatric Surgery did not fill the IFSO survey form but provided an official report on the performed interventions. The total number of surgical and endoluminal procedures performed in 2018 in the world was 696,191. Sleeve gastrectomy (SG) remained the most commonly performed bariatric procedure $(N=386,096 ; 55.4 \%)$. Among the total reported bariatric/metabolic interventions, $604,223(86.8 \%)$ were primary surgical and 29,167 (4.2\%) primary endoluminal operations; $62,801(9 \%)$ were revisional procedures.

Conclusions There was only a slight increase (10.317 procedures) in the total number of the reported bariatric interventions compared to the last IFSO survey. SG continues to be the most commonly performed operation since 2014. The one anastomosis gastric bypass (OAGB), currently the third most performed procedure after SG and Roux-en-Y gastric bypass (RYGB), continues to rise in popularity worldwide.
\end{abstract}

Keywords IFSO Survey $\cdot$ IFSO Chapters $\cdot$ Metabolic and Bariatric Surgery

\section{Introduction}

The International Federation for the Surgery of Obesity and Metabolic Disorders (IFSO) was founded in 1995 under the leadership of the Italian Professor Nicola Scopinaro. The

Luigi Angrisani

luigiangrisani@chirurgiaobesita.it

1 Public Health Department "Federico II" University of Naples, Naples, Italy

2 Gastrointestinal Unit, Department of Medicine, Surgery and Dentistry, University of Salerno, Salerno, Italy

3 Gastro-Obeso-Center Institute, São Paulo, Brazil

4 Brigham and Women's Hospital, Harvard Medical School, Boston, MA, USA

5 Flinders University, Adelaide, South Australia, Australia mission of IFSO is "to unify the global scientific, surgical and integrated health communities, for the purpose of dissemination of knowledge, collaboration and establishing universal standards of care for the treatment of individuals with adiposity-based chronic disease, and supporting surgeons and integrated health professionals in their clinical practice on morbidly obese patients." The increasing number of joined Societies, led to the establishment of "Chapters" resulting in a better organization of bariatric activities and collaboration with the local official authorities in the different regions of the world. From 2005 to 2008, the European Chapter (EC), the Latin American Chapter (LAC), the North American Chapter (NAC), and the Asia Pacific Chapter (APC) were officially approved. The last chapter named Middle East North African Chapter (MENAC) was created several years later, at the end of 2017. The first bariatric surgery survey was published in 2003 [1]; thereafter, other surveys have been periodically published [2-6] describing the number and type 
of the bariatric procedures performed in the world and, since 2008, in each IFSO Chapter. In every published survey, new insights are added, such as focusing on endoluminal [5] or revisional procedures [6] and tracing the evolution of bariatric surgery over time.

Since 2014, the IFSO Global Registry was introduced with the aim to provide data on patient-related factors such as age, gender, body mass index (BMI), and obesity-related diseases. The Fourth and Fifth IFSO Global Registry reports from 2018 and 2019 [7] described 394,431, and 833.687 operations reported by 51 and 61 countries, respectively and drew the demographic and clinical data of bariatric patients, the surgical treatments performed and outcomes achieved both for weight and effects on comorbidities.

This IFSO Survey 2018 had a different objective: to report the number and types of bariatric procedures performed in the world in 2018 and the trend analysis of bariatric surgical and endoluminal interventions for the last 10 years in each IFSO Chapter, focusing on similarities and differences among them. Considering that MENAC has been recently constituted, this is the first report including its bariatric activities. This survey has also been enriched with a special section of questions asking each IFSO Society about the existence of national guidelines for bariatric and metabolic surgery, national recommendations for preoperative gastroscopy, type of reimbursement received for bariatric/metabolic surgery, and patients with BMI $<35 \mathrm{~kg} / \mathrm{m}^{2}$.

\section{Methods}

The IFSO survey form 2018 was e-mailed by the IFSO Secretariat to all the national societies in April 2019. If available, the form required the societies to specify for each type of operation the number of primary and revisional procedures performed. Furthermore, the questionnaire asked about the source of provided data (National Registry, National survey, expert opinion, other) and the presence of national guidelines for bariatric and metabolic surgery and whether there was any recommendations for performing preoperative gastroscopy. A final section aimed at evaluating the type of reimbursement received for bariatric/metabolic operations and surgery on patients with $\mathrm{BMI}<35 \mathrm{~kg} / \mathrm{m}^{2}$.

The American Society for Metabolic and Bariatric Surgery (ASMBS) did not complete and submit the IFSO survey form but provided an official report describing the performed operations [8].

Data provided from National Registry, National survey, and expert opinion by the responding national societies were analyzed and compared to those reported in the IFSO 2016 survey.

\section{Results}

The IFSO survey form 2018 (Table 1) was sent to 65 IFSO national societies. Fifty-seven/65 (87.7\%) IFSO Societies completed and submitted the form. Costa Rica, Dominican Republic, Iceland, Jordan, Panama, Serbia, Singapore, and Uruguay did not respond despite several attempts to request that they do so. Seventeen out of $58(29.3 \%)$ IFSO Societies reported data from their National Registries, 17/58 (29.3\%) from national surveys and the remaining societies provided expert's estimations.

The total number of surgical and endoluminal procedures performed in 2018 in the world was 696,191. Sleeve gastrectomy (SG) remained the most commonly performed bariatric procedure $(N=386,096 ; 55.4 \%)$.Among the total reported bariatric/metabolic interventions, 604,223 (86.8\%) were primary surgical and 29,167 (4.2\%) primary endoluminal operations; 62,801 (9\%) were revisional procedures (both surgical and endoluminal).

Table 2 reported the number and the type of operations worldwide and in each IFSO Chapter.

Figure 1 showed the long-term trend, from 2008 to 2018 of the main bariatric/metabolic surgical operations and from 2016 to 2018 for endoluminal procedures.

\section{EC}

Among the 26 responding EC national Societies, 9 (34.6\%) provided data from national registries and 11 $(42.3 \%)$ from national surveys. The total number of bariatric/metabolic procedures declared by each EC member, the presence of national guidelines for bariatric and metabolic surgery, and of recommendation for the preoperative gastroscopy were shown in Table 3 . In $22 / 26$ $(84.6 \%)$, EC Societies obesity is officially recognized as a disease and 19/26 declared a public reimbursement (whole or in part) of procedures (Table 3); however, only 9/26 (34.6\%) Societies included the reimbursement for metabolic surgery and for surgery on patients with BMI $<35 \mathrm{~kg} / \mathrm{m}^{2}$.

The long-term trends from 2008 to 2018 of the main bariatric/metabolic surgical operations and from 2016 to 2018 for endoluminal procedures in EC were shown in Fig. 2a. Considering the last IFSO survey report [6], SG and RYGB plateaued and represented the first and second most commonly performed procedures, respectively. OAGB had a slight increase $(+2140 ;+1.5 \%)$, whereas adjustable gastric banding (AGB) continued to decrease $(-3402 ;-1.6 \%)$. Additionally, EP did not show any meaningful increment. 
Table 1 The IFSO survey form 2018

Societr/ Country:

1 - Are these data provided by a National Registry? YES/NO

2 - If NO please specify methods (national survey, expert opinion, other)

3 - Does your country have national guidelines for bariatric and metabolic surgery? YES/NO

4 -If YES do your national guidelines recommend preoperative gastroscopy? YES/NO

\begin{tabular}{|l|l|}
\hline \multicolumn{2}{|c|}{ Number and Type of procedures performed in your Country in 2018 } \\
\hline $\begin{array}{c}\text { SURGICAL PROCEDURES } \\
\text { please report the total number of surgical procedures. If avaiable, }\end{array}$ & \multicolumn{1}{c|}{ NUMBER } \\
\hline Adjustable Gastric Banding & Total : \\
& Primary : \\
\hline Rour-en-Y Gastric Bypass (RYGB) & Revisional : \\
(including banded RYGB) & Total : \\
\hline Sleeve Gastrectomy & Primary : \\
& Revisional : \\
\hline Biliopancreatic diversion (BPD) ${ }^{2}$ & Total : \\
\hline One Anastomosis Gastric Bypass (OAGB) & Primary : \\
\hline Other operations (please specify) & Revisional : \\
\hline
\end{tabular}


Table 1 (Continued)

\begin{tabular}{|c|c|}
\hline & $\begin{array}{l}\text { Primary : } \\
\text { Revisional : }\end{array}$ \\
\hline ENDOLUMINAI PROCEDURES & NUMBER \\
\hline $\begin{array}{l}\text { Intragastric Balloons (Orbera BIB, Elipse Allurion, Obalon, Spatz Adjustable } \\
\text { Balloon System, Heliospbere Bag) }\end{array}$ & $\begin{array}{l}\text { Total: } \\
\text { If available, please specify } \\
\text { each type }\end{array}$ \\
\hline Endoscopic transoral gastroplasty (POSE, Apollo overstiches) & $\begin{array}{l}\text { Total : } \\
\text { Primary : } \\
\text { Revisional : }\end{array}$ \\
\hline Endoscopic transoral revision of gastric bypass & $\begin{array}{l}\text { Total : } \\
\text { Primary : } \\
\text { Revisional : }\end{array}$ \\
\hline Other (specify) & $\begin{array}{l}\text { Primary : } \\
\text { Revisional : }\end{array}$ \\
\hline
\end{tabular}

1- Please include: Minigastric bypass (MGB); Omega loop Gastric Bypass ; Single anastomosis gastro-ileostonry (SAGI); Sleeve Ileal (SASI) Bypass

2- Please include: Standard Scopinaro BPD, Duodenal Switch (DS), One Anastomosis Duodena Switch, Single anastomosis duodeno-ileostony sleeve (SADIs), Intestinal Pylorus Sparing Surgery Single Anastomosis (SIPS) 
Table 1 (Continued)

Please cross your answer with a ' $\mathrm{X}$ ' to these 4 last questions:

1) Is obesity officially recognized as a DISEASE in your Country?

2) Do you have public reimbursement for bariatric surgery in your

Country?

3) Do you have private insurance reimbursement for banatric surgery in your Country?

4) Do you have any reimbursement for metabolic surgery for patients with BMI $<$ than 35 in your Country?

\section{NAC}

Canadian data were provided by its national registry. In the USA, an official report was prepared by ASMBS [8]. Obesity was recognized as a disease in both NAC members. Table 4 showed the total number of bariatric/metabolic procedures submitted by the two NAC members, the presence of national guidelines for bariatric and metabolic surgery and recommendation for the preoperative gastroscopy. Canada included reimbursement for metabolic surgery in patients with BMI < $35 \mathrm{~kg} / \mathrm{m}^{2}$, USA did not report this information (Table 4). The long-term trend from 2008 to 2018 of the main bariatric/ metabolic surgical operations and from 2016 to 2018 for endoluminal procedures in NAC was shown in Fig. 2b. SG had a considerable increase $(+32,143 ;+8.6 \%)$ compared to the IFSO 2016 survey, whereas the number of RYGB plateaued. AGB had a further decrease $(-5430 ;-2.8 \%)$ and EP did not show any meaningful increment. Canada did not declare any OAGB. In the ASMBS report, OAGB were not specifically collected but included in "Other procedures" [8].

\section{APC}

Among the 10 responding APC national Societies, 3 (30\%) provided data from national registries and $5(50 \%)$ from national surveys. The total number of bariatric/metabolic procedures declared by each APC Society, the presence of national guidelines for bariatric and metabolic surgery and recommendation for preoperative gastroscopy were shown in Table 5. In 6/10 (60\%) APC Societies, obesity is officially recognized as a disease and 4 of them declared a public reimbursement (whole or in part) of procedures (Table 5); however, only in 2 Societies, there is a reimbursement for metabolic surgery in patients with $\mathrm{BMI}<35 \mathrm{~kg} / \mathrm{m}^{2}$.

The long-term trend from 2008 to 2018 of the main bariatric/metabolic surgical operations and from 2016 to 2018 for endoluminal procedures in APC was shown in Fig. 2c. When compared to the IFSO survey 2016 [6], SG significantly decreased $(-20,672 ;-15 \%)$; on the contrary, OAGB had a noteworthy rise $(+4598 ;+16 \%)$. RYGB slightly increased $(+737 ;+3 \%)$ and EP reached $5 \%$ of total procedures.

Table 2 Number and type of surgical and endoluminal procedures performed in 2018 in the world and in IFSO Chapter

\begin{tabular}{llllll}
\hline & EC & NAC & APC & LAC & MENAC \\
\hline Adjustable gastric banding (AGB) & 4592 & 2780 & 1297 & 578 & 510 \\
Roux-en-Y gastric bypass (RYGB) & 48,872 & 47,078 & 9488 & 94,146 & 4.185 \\
Sleeve gastrectomy (SG) & 104,052 & 159,461 & 38,160 & 56,844 & 27.579 \\
One anastomosis gastric bypass (OAGB) & 21,962 & n.r. & 14,164 & 4044 & $\mathbf{9 7 5 7}$ \\
Biliopancreatic diversion (BPD) & 1322 & 2488 & 1103 & 1138 & $\mathbf{2 0 3 , 7 6 9}$ \\
Other surgical operations & 4110 & 5847 & 2807 & 810 & 455 \\
Intragastric balloons & 4829 & 5042 & 3359 & 13,034 & 772 \\
Other endoluminal procedures & 613 & n.r. & 195 & 555 & $\mathbf{4 6 9 6}$ \\
Total & $\mathbf{1 9 0 , 3 5 2}$ & $\mathbf{2 2 2 , 6 9 6}$ & $\mathbf{7 0 , 5 7 3}$ & $\mathbf{1 7 1 , 1 4 9}$ & $\mathbf{6 5 0 6}$ \\
\end{tabular}

European Chapter (EC), North American Chapter (NAC), Asia Pacific Chapter (APC), Latin American Chapter (LAC), Middle East North African Chapter (MENAC); not reported (n.r) 
Fig. 1 Long-term trend and total number of bariatric/metabolic surgical operations from 2008 to 2018 , and endoluminal procedures in the world from 2016 to 2018

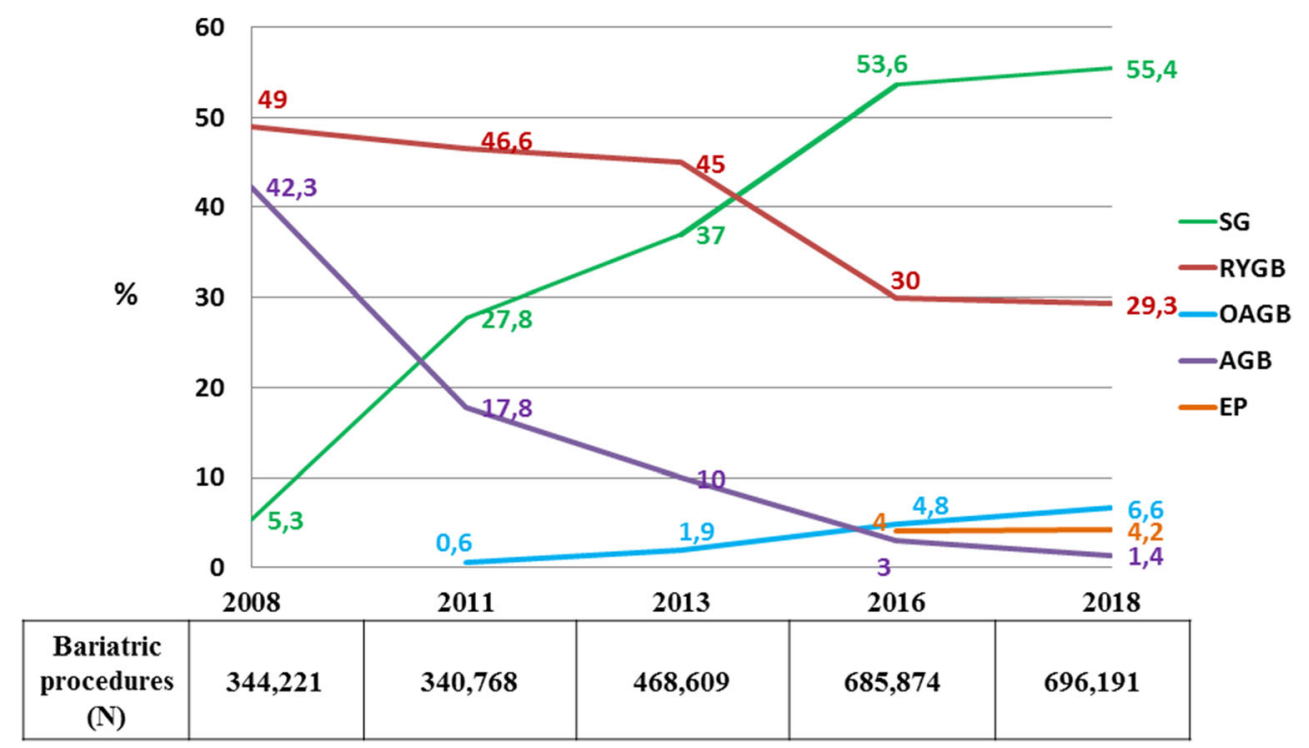

Table 3 Number of bariatric/metabolic procedures declared by EC Societies, the presence of national guidelines for bariatric and metabolic surgery, and recommendation for preoperative gastroscopy

\begin{tabular}{|c|c|c|c|c|c|c|}
\hline COUNTRY & & $\begin{array}{c}\text { NUMBER OF } \\
\text { BARIATRIC } \\
\text { PROCEDTRES }\end{array}$ & $\begin{array}{l}\text { NATIOXAL } \\
\text { GUIDEIES }\end{array}$ & $\begin{array}{l}\text { PREOPERATIVY } \\
\text { GASTROSCOPY }\end{array}$ & $\begin{array}{l}\text { OBESITYAAS } \\
\text { DISEASE }\end{array}$ & REMBBCRSEMTIT \\
\hline Austria & 를 & 531 & O & O & O & O \\
\hline Azerbaijan & 6 & 1.035 & $\Omega$ & $\Omega$ & $\Omega$ & $\Omega$ \\
\hline Belgiumn & प1 & 14.012 & O & 0 & O & O \\
\hline Czech Republic & 1 & 1.505 & O & O & 0 & 0 \\
\hline Finland & + & 1.052 & O & O & O & O \\
\hline France & 10 & 46.654 & $\widetilde{J}$ & 0 & 0 & $\Omega$ \\
\hline Cermany* & 0 & 15.186 & O & O & O & O \\
\hline Greece & 르 & 2.668 & O & O & O & O \\
\hline Iceland & 맘를 & 0 & & & & \\
\hline Israel* & $\frac{0}{0}$ & 7.604 & P & O & O & O \\
\hline Italy & 11 & 18.266 & O & 0 & 0 & 0 \\
\hline Kazalkhstan & +1 & 107 & 0 & 0 & 0 & 0 \\
\hline Lithuania & $=$ & 313 & 0 & O & O & $\mathrm{P}$ \\
\hline Netherlands: & 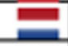 & 11.468 & 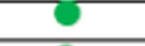 & 0 & 0 & 0 \\
\hline Norway & 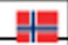 & 2.838 & O & P & O & O \\
\hline Poland & 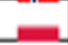 & 4.600 & O & O & O & O \\
\hline Portugal & s & 1.397 & 0 & O & O & P \\
\hline Romania & D1 & 1.655 & O & O & O & 운 \\
\hline Russian Federation* & & 1.997 & 0 & O & O & O \\
\hline Serbia & E & 0 & & & & \\
\hline Slovenia & 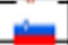 & 275 & 0 & O & O & O \\
\hline South Africa* & D를 & 515 & O & O & O & O \\
\hline Spain & 5 & 4.714 & O & P & P & P \\
\hline Sweden: & 믈 & 5.308 & O & O & $\Omega$ & P \\
\hline Switzerland* & +4 & 5.430 & O & O & O & O \\
\hline Turkey & C. & 33.589 & O & O & $\mathrm{P}$ & P \\
\hline Ularaine & $=$ & 239 & O & O & 0 & O \\
\hline Enited Kingdom* & S果訨 & 7394 & P & O & P & P \\
\hline TOTAL & & 190.352 & & & & \\
\hline
\end{tabular}

\section{* Data from National Registry}

Yes

No

\section{Partially}


a

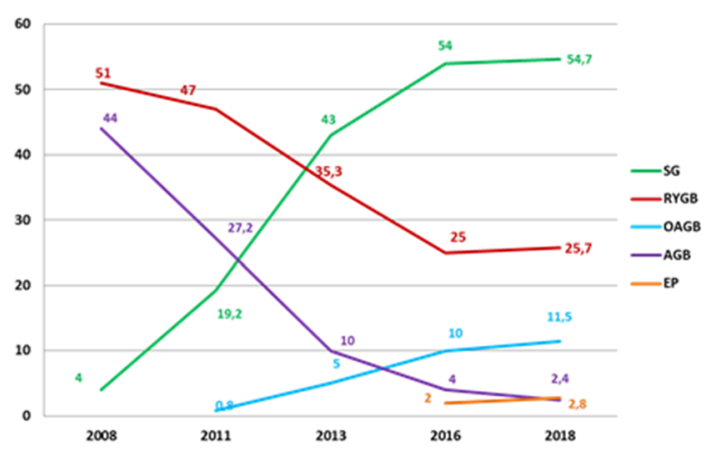

APC

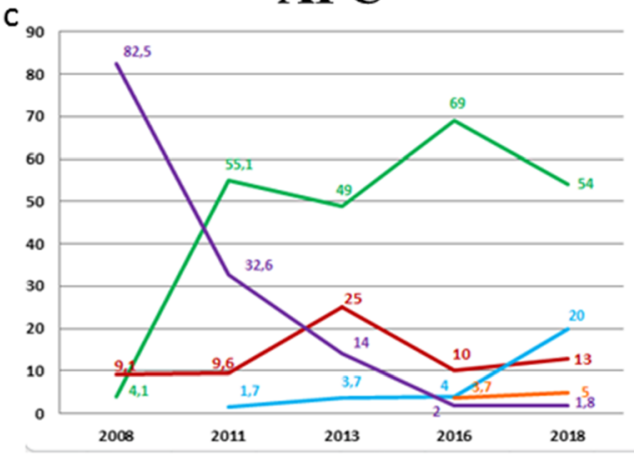

b

NAC

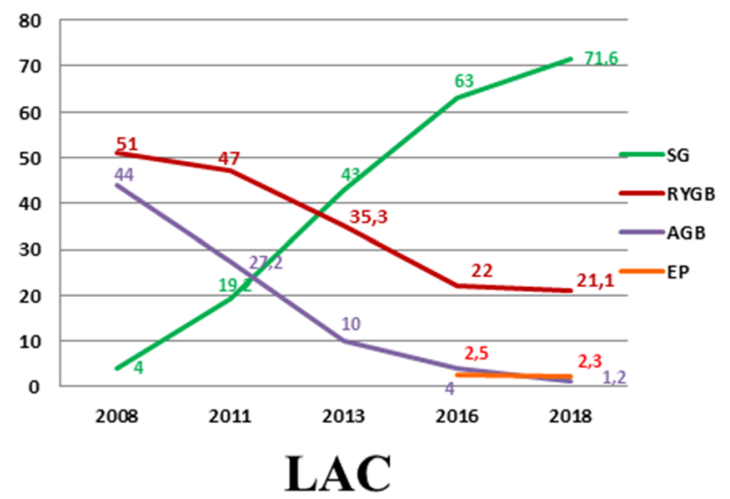

d

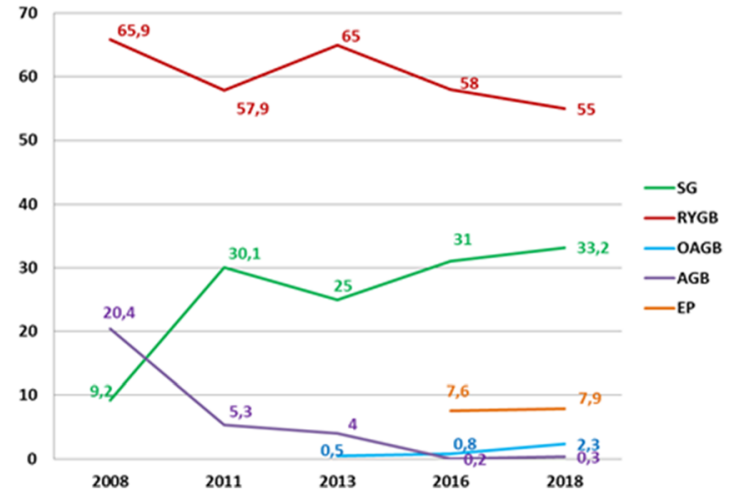

Fig. 2 Long-term trend, from 2008 to 2018 of the main bariatric/metabolic surgical operations and from 2016 to 2018 for endoluminal procedures in EC (3a), NAC (3b), APC (3c), and LAC (3d)

\section{LAC}

Among the 13 responding LAC national Societies, 3 (23\%) provided data from national registries and 3(23\%) from national surveys. The total number of bariatric/metabolic procedures declared by each LAC Society, the presence of national guidelines for bariatric and metabolic surgery, and recommendation for preoperative gastroscopy were shown in Table 6. In 9/13 (69\%) LAC members, obesity is officially recognized as a disease and 6 of them reported a reimbursement (whole or in part) of procedures (Table 6); however, only in 2 Societies, there is a reimbursement for metabolic surgery in patients with $\mathrm{BMI}<35 \mathrm{~kg} / \mathrm{m}^{2}$.

Table 4 Number of bariatric/metabolic procedures declared by NAC Societies, the presence of national guidelines for bariatric and metabolic surgery and recommendation for preoperative gastroscopy

\begin{tabular}{|c|c|c|c|c|c|c|}
\hline COUNTRY & & $\begin{array}{c}\text { NUMBER OF } \\
\text { BARIATRIC } \\
\text { PROCEDURES }\end{array}$ & $\begin{array}{l}\text { NATIONAL } \\
\text { GUIDELINES }\end{array}$ & $\begin{array}{l}\text { PREOPERATIVE } \\
\text { GASTROSCOPY }\end{array}$ & $\begin{array}{l}\text { OBESITY AS } \\
\text { DISEASE }\end{array}$ & REIMBURSEMENT \\
\hline Canada* & 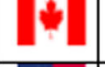 & 9.103 & 0 & ○ & O & 0 \\
\hline Usa & 瑟 & 213.593 & ? & 0 & 0 & n.r. \\
\hline TOTAL & & 222.696 & & & & \\
\hline
\end{tabular}

\section{* Data from National Registry}

Yes No Partially

n.r.= not reported 
Table 5 Number of bariatric/metabolic procedures declared by APC members, the presence of national guidelines for bariatric and metabolic surgery, and recommendation for preoperative gastroscopy

\begin{tabular}{|c|c|c|c|c|c|c|}
\hline COUNTRY & & $\begin{array}{l}\text { NUMBER OF } \\
\text { BARIATRIC } \\
\text { PROCEDURES }\end{array}$ & $\begin{array}{l}\text { NATIONAL } \\
\text { GUIDELINES }\end{array}$ & $\begin{array}{l}\text { PREOPERATIVE } \\
\text { GASTROSCOPY }\end{array}$ & $\begin{array}{l}\text { OBESITY AS } \\
\text { DISEASE }\end{array}$ & REIMBURSEMENT \\
\hline $\begin{array}{l}\text { Australia - New } \\
\text { Zealand* }\end{array}$ & 米. & 18.838 & 0 & 0 & ○ & O \\
\hline China & * & 9.839 & O & 0 & ○ & ○ \\
\hline Hong Kong & औ & 222 & 0 & 0 & 0 & 0 \\
\hline India & 6 & 20.242 & 0 & 0 & 0 & 0 \\
\hline Iran & 0 & 16.395 & 0 & O & 0 & 0 \\
\hline Japan* & & 648 & 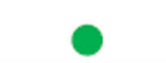 & 0 & - & - \\
\hline Korea & 8 & 573 & 0 & 0 & O & ○ \\
\hline Malaysia & 国 & 1.093 & O & O & O & O \\
\hline Phlippines & & 55 & 0 & 0 & 0 & 0 \\
\hline Singapore & IG & 0 & & & & \\
\hline Taiwan* & & 2.668 & 0 & 0 & ○ & O \\
\hline TOTAL & & 70.573 & & & & \\
\hline
\end{tabular}

* Data from National Registry
Yes

No

n.r:= not reported
The long-term trend from 2008 to 2018 of the main bariatric/ metabolic surgical operations and from 2016 to 2018 for endoluminal procedures in LAC was shown in Fig. 2d.

When compared to the previous IFSO survey [6], RYGB slightly declined $(+4171 ;-3 \%)$, but it remained the most commonly performed procedure. Specifically, in the IFSO survey 2016 were reported 89,975 RYGB that represented the $58 \%$ of all procedures $(N=153,106)$; in this survey were reported $94,146 \mathrm{RYGB}$ that represented the $55 \%$ of all procedures $(N=171,149)$. SG and OAGB had somewhat slight increases $(+10,375 ;+2.2 \%$, and $+2869,+1.5 \%$, respectively). EP represented the third most commonly performed bariatric procedures, reaching $7.9 \%$.

\section{MENAC}

This is the first IFSO survey report of MENAC activities since its foundation in 2017. Among the 6 responding MENAC national Societies, only Kuwait provided data from a national registry; the remaining reported expert opinions. Jordan did not add data about bariatric/metabolic procedures performed. However, they answered the questions on the form. Table 7 showed the total number of bariatric/metabolic procedures declared by each MENAC Society the presence of national guidelines for bariatric and metabolic surgery and recommendation for preoperative gastroscopy. In 3 of MENAC Societies $(42.7 \%)$, obesity is officially recognized as a disease and reported a reimbursement of procedures, although only one of them stated a partial reimbursement for metabolic surgery in patients with $\mathrm{BMI}<35 \mathrm{~kg} / \mathrm{m}^{2}$.

Bariatric/metabolic interventions were reported in Table 2. SG was the most commonly performed procedure $66.6 \%$, followed by OAGB (15\%), RYGB (10\%), and EP (4\%). AGB represented only $1.2 \%$ of interventions.

\section{Discussion}

This survey gave an updated snapshot of bariatric/metabolic surgery around the world in 2018 and described the trends of the main bariatric procedures performed in the last 10 years. 
Table 6 Number of bariatric/metabolic procedures declared by LAC members, the presence of national guidelines for bariatric and metabolic surgery, and of recommendation for preoperative gastroscopy

\begin{tabular}{|c|c|c|c|c|c|c|}
\hline COUNTRY & & $\begin{array}{c}\text { NUMABER OF } \\
\text { BARIATRIC } \\
\text { PROCEDURES }\end{array}$ & $\begin{array}{l}\text { NATIONAL } \\
\text { GUIDELINES }\end{array}$ & 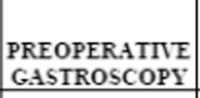 & $\begin{array}{c}\text { OBESITY AS } \\
\text { DISE.ASE }\end{array}$ & REIMBURSEMENT \\
\hline Argentina & $\because$ & 9.127 & 0 & 0 & 0 & 0 \\
\hline Bolivia & 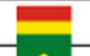 & 187 & O & O & O & O \\
\hline Brazil & $\theta$ & 118.320 & O & O & O & O \\
\hline Chile & 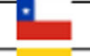 & 7.685 & O & $\mathrm{O}$ & O & O \\
\hline Colombia & 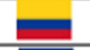 & 18.000 & O & $\Omega$ & O & O \\
\hline Costa Rica & & 0 & & & & \\
\hline Dominican Republic & 블 & 0 & & & & \\
\hline Ecuador & 흘 & 1.361 & 0 & O & O & O \\
\hline El Salvador* & & 211 & O & 0 & O & O \\
\hline Guatemala & $a^{3}$ & 343 & 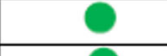 & O & O & 0 \\
\hline Honduras* & 름 & 145 & 0 & 0 & O & O \\
\hline Mexico & Dי & 9.331 & n.r. & n.r & n.r. & n.r. \\
\hline Panama & & 0 & & & & \\
\hline Paraguay & 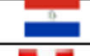 & 396 & 0 & O & 0 & O \\
\hline Perù & -1. & 3.800 & O & O & O & O \\
\hline Uruguay & $\cong$ & 0 & & & & \\
\hline Venezuela* & $m$ & 2.243 & 0 & 0 & 0 & 0 \\
\hline TOTAL & & 171.149 & & & & \\
\hline
\end{tabular}

* Data from National Registry

Yes
No Partially n.r. $=$ not reported
The total number of reported bariatric interventions had only a slight increase compared to the last 2016 IFSO survey $(696,191$ vs. 685,874$)$, just an increase of 10.317 procedures. This may have been influenced by the lack of data submission of 8 countries, and the small number of IFSO Societies $(17 / 58$, $29.3 \%$ ) reporting data from National Registries. The response rate in this survey, in fact, was slightly lower compared to the previous IFSO survey $(58 / 62,94 \%$ vs. $57 / 65,87.7 \%)$.

However, it is interesting to discuss the worldwide trends of bariatric procedures in the last decade. In 2008 the AGB was the second most performed procedure representing about $42.3 \%$ of all interventions. In the following years, AGB gradually declined, probably due to the high failure and reoperation rates. Compared to the 2016 IFSO report, it had a further decreased $(-1.6 \%)$ and was overtaken by OAGB and EP. Since 2014, the SG has continued to be the most commonly performed operation, probably due to its already reported advantages [6,9]. OAGB continues to rise in popularity and is now the third most performed procedure after SG and RYGB.
There are notable differences of frequency of the bariatric/ metabolic procedures among the IFSO Chapters that draw specific trend curves.

Compared to the 2016 IFSO report, SG has a marked increase $(+8.6 \%)$ only in the NAC, whereas it plateaued in EC and LAC and, even notably, decreased in APC (-15\%). The OAGB follows an opposite trend to SG. In fact, it significantly grew in popularity in APC $(+16 \%)$, was essentially stable in EC and LAC, and represented only a minority in NAC, where it was not considered a standard operative procedure and included in "Other procedures." [8] These differences might reflect the different attitudes of the local bariatric teams towards OAGB. Ramos et al. [10] recently published the results of a modified Delphi consensus study organized by IFSO on OAGB, that revealed that, despite the general agreement among surgeons about the safety and efficacy of OAGB, numerous "areas of non-consensus" still remained. It can be hypothesized that in the APC, bariatric surgeons recently have preferred the OAGB to the SG for a subgroup of obese bariatric surgery candidates. However, this was not the aim of this 
Table 7 Number of bariatric/metabolic procedures declared by MENAC members, the presence of national guidelines for bariatric and metabolic surgery, and of recommendation for preoperative gastroscopy

\begin{tabular}{|c|c|c|c|c|c|c|}
\hline COUNTRY & & $\begin{array}{l}\text { NUMBER OF } \\
\text { BARLATRIC } \\
\text { PROCEDURES }\end{array}$ & $\begin{array}{l}\text { NATIONAL } \\
\text { GUIDELINES }\end{array}$ & $\begin{array}{l}\text { PREOPERATIVE } \\
\text { GASTROSCOPY }\end{array}$ & $\begin{array}{c}\text { OBESITY AS } \\
\text { DISEASE }\end{array}$ & REIMBCRSEMENT \\
\hline Egypt & $=$ & 24.354 & 0 & 0 & 0 & O \\
\hline Iraq & 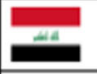 & 1.680 & 0 & 0 & O & O \\
\hline Jordan & $=$ & n.r. & 0 & 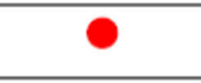 & O & 0 \\
\hline Kuwait* & 1 & 3.302 & 0 & 0 & 0 & 0 \\
\hline Lebanon & \% & 6.100 & ○ & 0 & O & O \\
\hline $\begin{array}{c}\text { Saudi } \\
\text { Arabia }\end{array}$ & $\operatorname{sen}$ & 757 & 0 & O & 0 & 0 \\
\hline UAE & E & 5.228 & n.r. & n.r. & n.r. & n.r. \\
\hline TOTAL & & 41.421 & & & & \\
\hline
\end{tabular}

* Data from National Registry

\section{Yes No Partially n.r:= not reported}

survey, since the analysis of demographic and clinical data of bariatric patients was reported by the IFSO Registry [7].

The RYGB trends also revealed interesting differences among the IFSO Chapters. In the LAC, it represented more than half of all bariatric operations performed in the last 10 years. In EC and NAC, it was the second most commonly performed procedure after SG. While in the APC, only a minority are performed and there was even a small decrease from $2016(-2 \%)$. Another peculiarity of the LAC was the higher number of EP than the other IFSO Chapters. EP represented $7.9 \%$ of all procedures. This may have been due to differences in the attitudes towards endoluminal techniques. It is likely that reimbursements for this type of procedures could have played a role.

The degree of recognition of obesity as a disease by different national authorities is reflected in the wide range of reimbursement for bariatric surgery.

In EC and NAC, obesity is officially recognized as a disease by more than $80 \%$ of members and there are specific guidelines and reimbursements. In LAC, except for Brazil, obesity is well recognized as a disease and there is universal coverage for bariatric surgery. In the APC and MENAC, this percentage is low and this could influence the local bariatric activities. The percentage of IFSO Societies where there is a reimbursement for metabolic surgery in patients with BMI $<35 \mathrm{~kg} / \mathrm{m}^{2}$ was even lower, despite a supportive IFSO Statement [11] and several scientific studies that support its efficacy and safety [12-15].

There are several limitations to these data. The most important limitation of this survey is that a source of data was an expert's estimation $(24 / 58,41.4 \%)$ rather than a report of National Registries (17/58, 29.3\%). Furthermore, 8/58 (13.8\%) IFSO Societies did not send any data. However, in the lack of a worldwide distribution of National Registries, this approach represents the best way to obtain a reliable picture of the real situation. Moreover, we did not ask to specify if there were any differences in the attitude towards the gastroscopy for the different type of procedure. However, according to a recent IFSO Position Statement [16], the gastroscopy should be considered before all bariatric procedures despite the presence or not of upper GI symptoms, due the $25.3 \%$ chance of an unexpected finding in asymptomatic patients, that may alter management or contra-indicate surgery.

Finally, this survey offers a snapshot of bariatric surgery performed worldwide before the outbreak of the novel coronavirus Sars COV2 pandemic (COVID 19), which has rapidly become a global health emergency [17] and significantly impacted health services. It will be very interesting to compare these data with those of future surveys, to understand how COVID 19 has been influencing bariatric surgeons in their activities. 
Acknowledgments We thank the Presidents of the responding IFSO National Societies and Manuela Mazzarella and Stefanie D'Arco of IFSO Secretariat for their support.

\begin{tabular}{|c|c|}
\hline IFSO Nation & President \\
\hline Argentina & Felipe Fiolo \\
\hline Australia - New Zealand & Michael Talbot \\
\hline Austria & Stephan Kriwanek \\
\hline Azerbaijan & Taryel Omarov \\
\hline Belgium & Thierry Lafullarde \\
\hline Bolivia & Jose Lizarazu \\
\hline Brazil & João Caetano Dallegrave Marchesini \\
\hline Canada* & Laurent Biertho \\
\hline Chile & Claudio Canales \\
\hline China & Cunchuan Wang \\
\hline Colombia & Eduardo Silva \\
\hline Czech Republic & Martin Fried \\
\hline Ecuador & Glenda Herrera \\
\hline Egypt & Alaa Abbass Moustafa \\
\hline El Salvador & Enrique Arias \\
\hline Finland & Anne Juuti \\
\hline France & Jerome Dargent \\
\hline Germany & Dieter Birk \\
\hline Greece & Harry Pappis \\
\hline Guatemala & Fernando Montufar \\
\hline Honduras & Ricardo Pena \\
\hline Hong Kong & Simon Wong \\
\hline India & Arun Prasad \\
\hline Iran & Mohammad Taleb Pour \\
\hline Iraq & Ramiz Sami Mukhtar \\
\hline Israel & Nasser Sakran \\
\hline Italy & Luigi Piazza \\
\hline Japan & Hisahiro Matsubara \\
\hline Jordan & Ahmad Sami Salem \\
\hline Kazakhstan & Oral Ospanov \\
\hline Korea & Joo-Ho Lee \\
\hline Kuwait & Mohammed Al-Jarallah \\
\hline Lebanon & Georges Al Hajj \\
\hline Lithuania & Almantas Maleckas \\
\hline Malaysia & Nik Ritza Kosai \\
\hline Mexico & Miguel Herrera \\
\hline Netherlands & Ronald Liem \\
\hline Norway & Jorunn Sandvik \\
\hline Paraguay & Ricardo Olmedo \\
\hline Perù & Ramiro Carbajal \\
\hline Phlippines & Edward Oliveros \\
\hline Poland & Mariusz Wylezol \\
\hline Portugal & Jorge Santos \\
\hline Romania & Niculae Iordache \\
\hline Russian Federation & Aleksandr Neimark \\
\hline Saudi Arabia & Khalid Mirza Gari \\
\hline Slovenia & Tadeja Pintar (co-President) \\
\hline
\end{tabular}

$\begin{array}{ll}\text { South Africa } & \text { Maria-Teresa Van der Merwe } \\ \text { Spain } & \text { José Antonio Ramirez Felipe } \\ \text { Sweden } & \text { Torsten Olbers } \\ \text { Switzerland } & \text { Ralph Peterli } \\ \text { Taiwan } & \text { Weu Wang } \\ \text { Turkey } & \text { Mustafa Sahin } \\ \text { Ukraine } & \text { Andriy S. Lavryk } \\ \text { UAE } & \text { Abdul wahid Alwahedi } \\ \text { United Kingdom } & \text { David Kerrigan } \\ \text { Usa } & \text { Eric De Maria } \\ \text { Venezuela } & \text { Salvador Navarrete }\end{array}$

\section{Compliance with Ethical Standards}

Conflict of Interest The authors declare that they have no conflicts of interest.

Ethical Approval This article does not contain any studies with human participants or animals performed by any of the authors.

\section{References}

1. Buchwald H, Williams SE. Bariatric surgery worldwide 2003. Obes Surg. 2004;14(9):1157-64. https://doi.org/10.1381/ 0960892042387057.

2. Buchwald H, Oien DM. Metabolic/bariatric surgery Worldwide 2008. Obes Surg. 2009;19(12):1605-11. https://doi.org/10.1007/ s11695-009-0014-5.

3. Buchwald H, Oien DM. Metabolic/bariatric surgery worldwide 2011. Obes Surg. 2013;23(4):427-36. https://doi.org/10.1007/ s11695-012-0864-0.

4. Angrisani L, Santonicola A, Iovino P, et al. Bariatric surgery worldwide 2013. Obes Surg. 2015;25(10):1822-32. https://doi.org/10. 1007/s11695-015-1657-z.

5. Angrisani L, Santonicola A, Iovino P, et al. Bariatric surgery and endoluminal procedures: IFSO worldwide survey 2014. Obes Surg. 2017;27(9):2279-89. https://doi.org/10.1007/s11695-017-2666-x.

6. Angrisani L, Santonicola A, Iovino P, et al. IFSO Worldwide survey 2016: Primary, endoluminal, and revisional procedures. Obes Surg. 2018;28(12):3783-94. https://doi.org/10.1007/s11695-0183450-2.

7. Welbourn R, Hollyman M, Kinsman R, et al. Bariatric surgery worldwide: baseline demographic description and one-year outcomes from the fourth IFSO Global Registry Report 2018. Obes Surg. 2019;29(3):782-95. https://doi.org/10.1007/s11695-0183593-1.

8. English WJ, DeMaria EJ, Hutter MM, et al. American Society for Metabolic and Bariatric Surgery 2018 estimate of metabolic and bariatric procedures performed in the United States. Surg Obes Relat Dis Off J Am Soc Bariatric Surg. 2020;16(4):457-63. https://doi.org/10.1016/j.soard.2019.12.022.

9. Angrisani L. 2014: The year of the sleeve supremacy. Obes Surg. 2017;27(6):1626-7. https://doi.org/10.1007/s11695-017-2681-y.

10. Ramos AC, Chevallier JM, Mahawar K, et al. IFSO (International Federation for Surgery of Obesity and Metabolic Disorders) Consensus Conference Statement on One-Anastomosis Gastric Bypass (OAGB-MGB): results of a modified Delphi Study. Obes Surg. 2020;30(5):1625-34. https://doi.org/10.1007/s11695-02004519-y. 
11. Busetto L, Dixon J, De Luca M, et al. Bariatric surgery in class I obesity : a position statement from the International Federation for the Surgery of Obesity and Metabolic Disorders (IFSO). Obes Surg. 2014;24(4):487-519. https://doi.org/10.1007/s11695-014-1214-1.

12. Cummings DE, Cohen RV. Bariatric/metabolic surgery to treat type 2 diabetes in patients with a BMI $<35 \mathrm{~kg} / \mathrm{m}^{2}$. Diabetes Care. 2016;39(6):924-33. https://doi.org/10.2337/dc16-0350.

13. Vitiello A, Angrisani L, Santonicola A, et al. Bariatric surgery versus lifestyle intervention in class I obesity: 7-10-year results of a retrospective study. World J Surg. 2019;43(3):758-62. https://doi. org/10.1007/s00268-018-4847-8.

14. Buchwald $\mathrm{H}$. The evolution of metabolic/bariatric surgery. Obes Surg. 2014;24(8):1126-35. https://doi.org/10.1007/s11695-0141354-3.

15. Rubino F, Nathan DM, Eckel RH, et al. Metabolic surgery in the treatment algorithm for type 2 Diabetes: a joint statement by international diabetes organizations. Diabetes Care. 2016;39(6):861-77. https://doi.org/10.2337/dc16-0236.

16. Brown WA. Johari Halim Shah Y, Balalis G, Bashir A, Ramos A, Kow L, Herrera M, Shikora S, Campos GM, Himpens J, Higa K.
IFSO Position statement on the role of esophago-gastro-duodenal endoscopy prior to and after bariatric and metabolic surgery procedures. Obes Surg. 2020;30(8):3135-53. https://doi.org/10.1007/ s11695-020-04720-z.

17. WHO. https://www.who.int/emergencies/diseases/novelcoronavirus-2019/events-as-they-happen.

During the final editing process of this manuscript, the entire world of bariatric and metabolic surgery was frozen by the Nicola Scopinaro's death. He was the IFSO founder, its first President and first Honorary President and the Author of the first worldwide IFSO Survey series. We will always miss his rigorous research method, his open mind, and forward vision.

Publisher's Note Springer Nature remains neutral with regard to jurisdictional claims in published maps and institutional affiliations. 